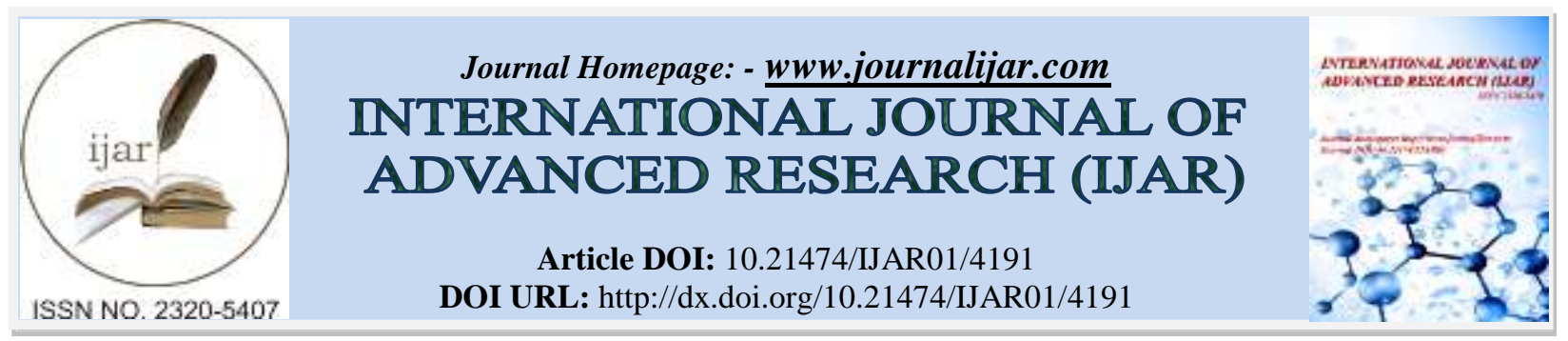

RESEARCH ARTICLE

\title{
CLIMATE CHANGE AND TYPE 2 DIABETES MELLITUS
}

\author{
Harmanjot Kaur ${ }^{1}$ and Roopjot Kochar ${ }^{2}$ \\ 1. Associate Professor (Food Science and Nutrition), University School Hotel Management, Desh Bhagat \\ University, Mandi Gobindgarh . \\ 2. Ayurvedic Physician and Nutritionist, 78/13 Anant Nagar, Khanna-141401.
}

\section{Manuscript Info}

Manuscript History

Received: 19 March 2017

Final Accepted: 20 April 2017

Published: May 2017

Key words:-

Climate changes, global impact, Type 2 diabetes, comorbid conditions, metabolic syndrome, Geo environmental Diabetology.

\begin{abstract}
Diabetes is a global epidemic impacting the lives of many people on a daily basis. At present, it is estimated that 422 million people are living with diabetes globally and this number is expected to double by the year 2030. Diabetes currently affects more than 62 million Indians, which is more than 7.1 per cent of the adult population. Nearly one million Indians die due to diabetes every year. According to the Indian Heart Association, India is projected to be home to 109 million individuals with diabetes by 2035 . The high incidence is attributed to a combination of genetic susceptibility plus adoption of a high-calorie, low-activity lifestyle by India's growing middle class. Paralleling the epidemic of type 2 diabetes is the phenomena of climate change, which has long been overlooked. The effects of climate change are observable today through variable weather patterns such as long periods of extreme heat, drought, disasters and rising sea levels, to name a few. Together, these global issues are impacting the health and well-being of the world's most vulnerable populations, especially the health of women, children, the elderly, the poor and those in low socio-economic statuses and those with underlying health conditions. By observing the global impact of climate change on type 2 diabetes and the future changes in this metabolic disorder's prevalence and incidence that may ensue, researchers may be able to curtail the detrimental effects of the associated comorbid conditions associated with diabetes (such as hypertension, cardiovascular disease and the Metabolic Syndrome) amongst the world's most susceptible individuals.
\end{abstract}

Copy Right, IJAR, 2017,. All rights reserved.

\section{Introduction:-}

Geoenvironmental diabetology is defined more specifically as the study of how geophysical phenomena impact a patient with diabetes, to include effects on metabolic control, ancillary equipment (e.g., glucometers and insulin pumps), medications, supplies, access to care, and influences on the adaptive strategies employed by patients to care for their diabetes under extreme circumstances. Geological events such as natural disasters (e.g., earthquakes) or extreme weather (e.g., heat waves) are examples of stressors that can affect patients with diabetes and that can be included under the heading of geoenvironmental diabetology. As the global prevalence of diabetes continues to increase, including in parts of the world that are especially vulnerable to disasters and climate change, further discussion is warranted on how to best prepare for management of diabetes under conditions of extreme geological 
and weather events and a changing climate(Curtiss, 2011). Globally, an estimated 422 million adults are living with diabetes mellitus, according to the latest 2016 data from the World Health Organization (WHO, 2016).Diabetes prevalence is increasing rapidly; previous 2013 estimates from the International Diabetes Federation (2016) put the number at 381 million people having diabetes. The number is projected to almost double by 2030 (Wild S, 2004 ). Type 2 diabetes makes up about 85-90\% of all cases (Agardh E, 2011). Increases in the overall diabetes prevalence rates largely reflect an increase in risk factors for type 2, notably greater longevity and being overweight or obese (Curtiss, 2011). Diabetes mellitus occurs throughout the world, but is more common (especially type 2) in the more developed countries. The greatest increase in prevalence is, however, occurring in low and middle income countries including in Asia and Africa, where most patients will probably be found by 2030 (Wild S, 2004). The increase in incidence in developing countries follows the trend of urbanization and lifestyle changes, including increasingly sedentary lifestyles, less physically demanding work and the global nutrition transition, marked by increased intake of foods that are high energy-dense but nutrient-poor often high in sugar and saturated fats, sometimes referred to as the Western pattern diet(Curtiss, 2011; Wild S,2004). The risk of getting type 2 diabetes has been widely found to be associated with lower socio-economic position across countries (Agardh E, 2011). About 3.8 million people in the United Kingdom have diabetes mellitus, but the charity Diabetes U.K. have made predictions that could become high as 6.2 million by $2035 / 2036$. The NHS spent a daily average of $£ 2.2 \mathrm{~m}(€ 2.6 \mathrm{~m}$; $\$ 3.7 \mathrm{~m})$ in 2013 on prescriptions for managing diabetes in primary care, and about $10 \%$ of the primary care prescribing budget is spent on treating diabetes (Gareth I, 2014). Diabetes U.K. have also predicted that the National Health Service could be spending as much as 16.9 billion pounds on diabetes mellitus by 2035, a figure that means the NHS could be spending as much as $17 \%$ of its budget on diabetes treatment by 2035 (Diabetes UK, 2012).Medical nutrition therapy is integral to diabetes care and management (Hajime I, 2001). Balance between dietary intake and energy consumption through daily physical activities is the most influential factor in the glycemic control of type 2 diabetic patients. The nutritional prescription made for a diabetic individual is usually determined by taking into consideration the expected physical activity, diabetes complication(s) and age.

\section{Effect of climate change on type 2 diabetes mellitus:-}

Diabetes and climate change are directly linked through various pathways. People with diabetes suffer serious outcomes with change in climate. The seasonal variation in HbA1c levels has been observed among type 2 diabetic patients that are likely to be caused by an increased dietary calorie intake and decreased physical activity during the cold winter months. It seems reasonable for diabetologists and dietitians to modify the nutritional prescription for those diabetic patients whose opportunities for physical exercise are reduced during the winter months (Hajime I, 2001).Diabetes increases vulnerability to dehydration, heatstroke and cardiovascular events during heat waves. Climate shocks and disasters such as floods and storms threaten health system and weaken capacity for diabetes prevention and management. After hurricane Katrina2005, the vulnerable people with chronic conditions such as diabetes are left without access of any kind of equipped health system in small island states such as those in pacific islands increasingly facing dual threat of climate extremes and devastating diabetes prevalence rates. Climate change also increases the diabetes risk factors. Climate extremes damage agricultural production and food security. It is estimated as the rising temperature effect the food production half of the world will suffer food shortage. Food insecurity also possesses threat to mothers and children whose risk of Diabetes type 2 increases in later life if malnourished during pregnancy. The World Health Organization (WHO) estimates that the last 30 years of anthropogenic climate change has resulted in more than 150,000 deaths annually (Katie D, 2012; Kovats RS, 2005). Potential health impacts of climate change include temperature-related morbidity and mortality, injuries due to extreme weather event (i.e. flooding, tornadoes, hurricanes, and drought), water, food, and vector-borne infectious diseases, and respiratory and cardiovascular problems due to worsening air pollution and increased aero-allergen production (Haines A, 2006). People with underlying medical conditions such as diabetes are more vulnerable to the adverse health impacts of climate change. In hotter temperatures, dehydration and heatstroke increases morbidity and mortality in people with diabetes. People with diabetes are predisposed to cardiovascular events during heat waves and higher mortality from heart attack on days of high air pollution (Michael A and Maria M, 2001).Indirect effects of climate change can lead to malnourishment and starvation due to crop shortages, conflicts and increased urbanization due to demographic shifts in populations (Frumkin J, 2008). The health outcomes of climate change will disproportionately affect those more vulnerable -- including children, elderly, the socially isolated, and persons with chronic disease and mental health. Diabetes in women and diabetes in pregnancy (gestational diabetes) also needs to be explored in a more specific focus in relation to climate change. Gestational diabetes in women with multiple pregnancies and the likelihood of their children developing diabetes regardless of childhood nutrition should also be explored. Before climate change and diabetes can be connected further, more overall foundation knowledge on the development of diabetes in women living in rural areas needs to be explored. Socioeconomic 
status (SES) plays a large factor in health status and can change how one perceives their own health to be. Women who are pregnant and socioeconomically disadvantaged (i.e., in low socio economic status/SES) may experience diabetes in a way that is distinct from their counterparts who are well off (i.e., in higher SES). It is possible that women of low SES may experience nutritional scarcity in times of food surplus. This may be due in part to the cultural and social norms of providing food for their spouses and their children before their own needs, but also may be largely due to food insecurity attributable to low SES (Mamdouh M, 2013).The International Diabetes Federation has recognized that diabetes and climate change are two inter-related epidemics impacting human health at an accelerated rate. These concerns are addressed in a report compiled by the federation that emphasizes the increased risk for low and middle income countries (International Diabetes Federation, 2016). It has been established that these increased risks are caused by the impact that extremes in climate have on agriculture production, which in turn threaten food security. Agriculture is most vulnerable to the impacts of climate change due to its high reliance on weather. Extreme weather events as a result of climate change are a cause of great concern for those reliant on agriculture for food and income. In recent decades, the impacts of climate change have been felt by the Asia-Pacific region with more intense and frequent weather events such as droughts, cyclones, floods, and hailstorms (Mamdouh M, 2013).Consequently, crop production fails and food shortage occurs.

\section{Conclusion:-}

Geological and other environmental variables can negatively affect patients with diabetes, having impact on such important variables as metabolic control, equipment performance, quality of life, access to medical care, mortality, and health care utilization. While the impact of natural disasters and weather extremes on the diabetes patient can potentially be tempered with enhanced national planning, educational programs on preparedness, and individual readiness, effects of other environmental stressors on the diabetes patient, such as air pollution and climate change, are not as easily mitigated, and the reversal of these forces require major shifts in national and global policy.

\section{References:-}

1. Agardh, E. (2011): Type 2 diabetes incidence and socio-economic position: a systematic review and metaanalysis. Int. J.Epidemiol., 40(3): 804-818.

2. Curtiss, B.C., Wellik, K.E. and Fowke, M.(2011):Geoenvironmental Diabetology. J. Diabetes. Sci. Technol., 5(4): 834-842.

3. International Diabetes Federation.(2016): Diabetes in Pregnancy: Protecting Maternal Health. Retrieved on April 10, 2017.

4. Diabetes UK. (2012): NHS spending on diabetes to reach $£ 16.9$ billion by 2035. 04-25.

5. Frumkin, J., Hess, J., Luber, G., Malilay, J. and McGeehin, M. (2008): Climate Change: The Public Health Response. Am. J. Pub. Healt., 98(3): 435-445.

6. Gareth, I. (2014): Diabetes prescribing in England consumes nearly $10 \%$ of primary care budget. BMJ., 349: g5143.

7. Haines, A., Kovats, R.S., Campbell-Lendrum, D. and Corvalan C. (2006): Climate Change and Human Health: Impacts, Vulnerability and Public Health. Pub. Healt., 120(7): 585-596.

8. Hajime, I., Hodaka, S., Tsuneharu, B., Keiko, N. and Tsuyoshi, W. (2001): Seasonal Variation of Glycemic Control in Type 2 Diabetic Patients. Diab. Care., 24(8): 1503-1503.

9. Katie, D. and Lucy, H.(2012): Diabetes and climate change - Two interconnected global challenges. Diab. Res. Clinic. Prac., 97(2): 337-339.

10. Mamdouh, M., Muhiuddin, H. and Maariya, B. (2013): Climate Change and Type 2 Diabetes . J. Endocrinol. Diab. Mellit., 1: 22-26.

11. Michael, A. and Maria, M. (2001): Potential impacts of climate variability and change on temperature-related morbidity and mortality in the United States. Environmentl. Healt. Persp.,109 (Suppl 2): 185-189

12. World Health Organization. (2016): Global Report on Diabetes. Geneva. 12-88.

13. Wild, S., Roglic, G., Green, A., Sicree, R. and King, H. (2004): Global prevalence of diabetes Estimates for the year 2000 and projections for 2030. Diab. Care. 27 (5): 1047-1053. 